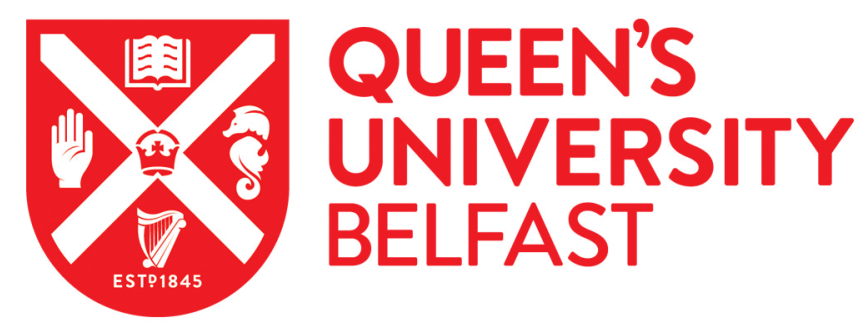

\title{
Personnel radiation dose considerations in the use of an integrated PET-CT scanner for radiotherapy treatment planning of an integrated PET-CT scanner for radiotherapy treatment planning
}

Carson, K. J., Young, V. A. L., Cosgrove, V. P., Jarritt, P. H., \& Hounsell, A. R. (2009). Personnel radiation dose considerations in the use of an integrated PET-CT scanner for radiotherapy treatment planning of an integrated PET-CT scanner for radiotherapy treatment planning. British Journal of Radiology, 82(983), 946-949.

https://doi.org/10.1259/bjr/73200201

Published in:

British Journal of Radiology

Document Version:

Publisher's PDF, also known as Version of record

Queen's University Belfast - Research Portal:

Link to publication record in Queen's University Belfast Research Portal

Publisher rights

http://www.birpublications.org/page/licensetopublish

\section{General rights}

Copyright for the publications made accessible via the Queen's University Belfast Research Portal is retained by the author(s) and / or other copyright owners and it is a condition of accessing these publications that users recognise and abide by the legal requirements associated with these rights.

Take down policy

The Research Portal is Queen's institutional repository that provides access to Queen's research output. Every effort has been made to ensure that content in the Research Portal does not infringe any person's rights, or applicable UK laws. If you discover content in the

Research Portal that you believe breaches copyright or violates any law, please contact openaccess@qub.ac.uk. 


\title{
Personnel radiation dose considerations in the use of an integrated PET-CT scanner for radiotherapy treatment planning
}

\author{
${ }^{1} \mathrm{~K} J$ CARSON, PhD, ${ }^{2} \mathrm{~V}$ A L YOUNG, DCR, ${ }^{3} \mathrm{~V}$ P COSGROVE, PhD, ${ }^{1} \mathrm{P}$ H JARRITT, PhD and ${ }^{3} \mathrm{~A}$ R HOUNSELL, PhD \\ ${ }^{1}$ Medical Physics Agency, Royal Group of Hospitals, Grosvenor Road, and ${ }^{2}$ Radiation Oncology and ${ }^{3}$ Medical Physics \\ Agency, Northern Ireland Cancer Centre, Belfast City Hospital, Belfast
}

\begin{abstract}
The acquisition of radiotherapy planning scans on positron emission tomography (PET)-CT scanners requires the involvement of radiotherapy radiographers. This study assessed the radiation dose received by these radiographers during this process. Radiotherapy planning ${ }^{18} \mathrm{~F}$-fluorodeoxyglucose ( $\left.{ }^{18} \mathrm{~F}-\mathrm{FDG}\right) \mathrm{PET}-\mathrm{CT}$ scans were acquired for 28 non-small cell lung cancer patients. In order to minimise the radiation dose received, a two-stage process was used in which the most timeconsuming part of the set-up was performed before the patient received their ${ }^{18} \mathrm{~F}-\mathrm{FDG}$ injection. Throughout this process, the radiographers wore electronic personal dosemeters and recorded the doses received at different stages of the process. The mean total radiation dose received by a radiotherapy radiographer was $5.1 \pm 2.6 \mu \mathrm{Sv}$ per patient. The use of the two-stage process reduced the time spent in close proximity to the patient by approximately a factor of four. The two-stage process was effective in keeping radiation dose to a minimum. The use of a pre-injection set-up session reduces the radiation dose to the radiotherapy radiographers because of their involvement in PET-CT radiotherapy treatment planning scans by approximately a factor of three.
\end{abstract}

Received 30 August 2008
Revised 23 October 2008 Accepted 24 October 2008

DOI: $10.1259 / \mathrm{bjr} / 73200201$

(C) 2009 The British Institute of Radiology
A fundamental requirement for successful radiotherapy is the accurate definition of target volumes within the treatment planning process. This is especially important for new treatment techniques such as conformal therapy and intensity-modulated radiation therapy. Recently, a number of studies have shown the potential benefit of incorporating functional information from positron emission tomography (PET) images into the radiotherapy treatment planning (RTP) process $[1,2]$. The standard imaging technique used in RTP is X-ray $\mathrm{CT}$, as it provides both good anatomical detail for defining the target volumes and the electron density information required for dose calculations. Any other images that are used in RTP must be registered to the RTP CT. Combined PET-CT scanners provide the opportunity to acquire inherently registered radiotherapy planning PET and CT images. These images may be obtained using either a standard PET-CT scan (preferably acquired with the patient in the treatment position), which is later registered with a planning CT scan, or a dedicated radiotherapy planning PET-CT scan, with the patient immobilised exactly as they would be for treatment. The advantages of using a dedicated PET-CT RTP scan are that it (i) avoids the introduction of additional uncertainties owing to image registration; (ii) reduces the resource requirement, as a separate planning $\mathrm{CT}$ scan is not acquired; and (iii) reduces the radiation

Address correspondence to: Kathryn Carson, Nuclear Medicine Department, Level 1, Imaging Centre, Royal Victoria Hospital, Belfast BT12 6BA, UK. E-mail: kathryn.carson@mpa.n-i.nhs.uk dose to the patient from acquiring multiple scans. However, it does require the involvement of radiotherapy radiographers in the PET scanning process. This is a relatively new role for these radiographers and raises the possibility of them receiving radiation doses additional to those received during their normal work. It should be noted that the radiation dose arising from performing the set of "hands on" procedures required for radiotherapy planning, when this is undertaken on a radioactive patient, is an additional occupational dose above that which would normally be received during diagnostic PET-CT scanning. The magnitude of these doses is required for workforce planning and needs to be assessed if PET-CT scanning for radiotherapy planning is to become a routine clinical service. This paper reports on the radiation doses received by radiotherapy radiographers as a result of their involvement in planning scans for non-small cell lung cancer (NSCLC) patients using ${ }^{18}$ F-fluorodeoxyglucose $\left({ }^{18} \mathrm{~F}-\mathrm{FDG}\right)$.

\section{Methods}

Radiotherapy planning PET-CT scans were acquired for 28 NSCLC patients who had been recruited into an ethically approved research study. Inclusion into this study required the patient to have had a staging PET-CT scan and to be intended for radical radiotherapy. Patients received $375 \mathrm{MBq}{ }^{18} \mathrm{~F}-\mathrm{FDG}$ and were positioned on the scanner bed after an uptake time of $45 \mathrm{~min}$. The scans were performed with a GE Discovery LS PET-CT 
scanner (GE Healthcare), using standard whole-body imaging scanning parameters; however, as the scan was specifically for radiotherapy planning purposes, it extended only over the lungs and was thus of a shorter duration than a routine whole-body scan (10-15 min compared with 30-35 min). The patients were positioned exactly as they would be for treatment, with the aid of a flat couch top and immobilisation device (MedTec thorax board; MedTec, Orange City, IA), by the radiotherapy radiographers. External fixed lasers were used to aid patient set-up. The equipment and patient positioning used are standard techniques within radiotherapy but are more rigorous than would usually be required for diagnostic imaging. The radiographers also make permanent marks on the patient's skin. These provide a reference between the internal anatomy of the patient represented in the PET and CT images and an external landmark, which is used to position the patient for treatment. All other patient care, e.g. injection and care after the scan, was performed by PET scanner staff as normal.

The care required in setting up a patient for a radiotherapy treatment planning scan can result in a significant amount of time being spent in close contact with the patient. We have previously reported a technique designed to reduce the potential radiation dose to the radiotherapy radiographers by minimising the time spent with the patient after injection of ${ }^{18}$ F-FDG [3]. Figure 1 illustrates this process, which is briefly described here for clarity. The most time-consuming part of the process is in the initial set-up of the patient on the scanner, as this is the first time that the patient has been in the treatment position. Therefore, this was carried out before the patient

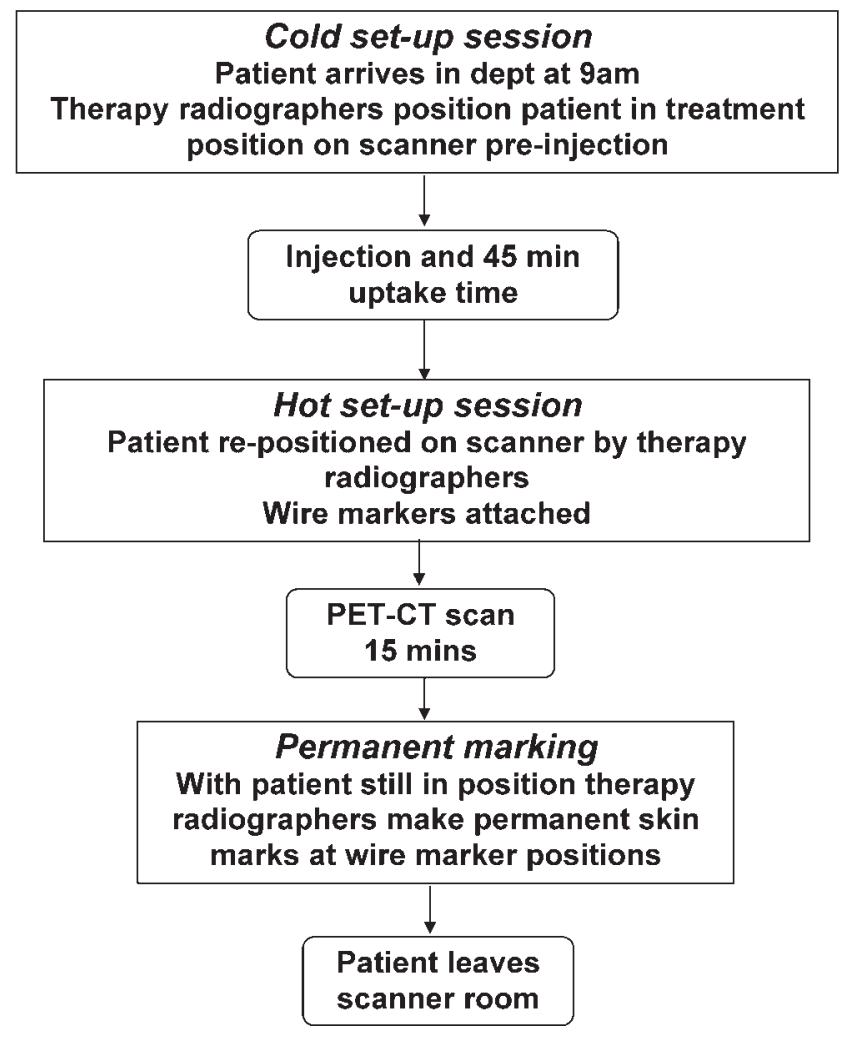

Figure 1. Process used to perform radiotherapy treatment planning positron emission tomography (PET)-CT scans. had their ${ }^{18}$ F-FDG injection - the "cold set-up session". This also allowed time for the radiographers to talk to the patient. These radiographers generally work in pairs, to allow verification of patient set-up. All but one of the patients were set up by two radiographers working together. The radiographers marked the patient's skin non-permanently and made a careful note of the patient's position on the immobilisation device on the scanner, so that the patient could be quickly and accurately repositioned after injection. The patient was then moved from the PET-CT couch to a separate injection and preparation room. The patient was injected by the nuclear medicine staff and remained under their supervision and care during the uptake period and their visit to the toilet before they returned to the PET scanning room for their radiotherapy planning scan.

At this stage, the patient was re-positioned on the scanner by the radiotherapy radiographers as quickly as possible using the set-up information determined during the "cold set-up session". During this "hot set-up session", radio-opaque markers were attached over the non-permanent marks on the skin. These markers were not attached earlier in case they moved during the uptake phase. When the set-up was complete, the nuclear medicine staff acquired the PET-CT images. The total time on the scanner was $15-20 \mathrm{~min}$. On completion of the PET-CT scan, the radiographers made permanent marks on the patient's skin at the positions of the radio-opaque markers.

Each radiotherapy radiographer wore an electronic personal dosemeter (EPD) at waist level throughout this process, and the radiation doses measured during each stage were recorded. An annual calibration of the EPDs used (Siemens mark 2.3 (Siemens, Germany) or Stephens Mini 6100 (Stephens, UK)), which was traceable to national primary standards, was performed. Different pairs of radiotherapy radiographers (from a pool of five) were involved in the PET-CT scanning for different patients, although one radiographer was involved with 25 of the 28 patients in the study. At all times, the radiotherapy radiographers tried to minimise the time they spent in close contact with the patient, and they increased their distance from the patient whenever possible.

\section{Results}

The "cold set-up session" typically lasted $20 \mathrm{~min}$, whereas patient re-positioning during the "hot set-up session" took an average of $5 \mathrm{~min}$ and permanent marking took on average $4 \mathrm{~min}$. Therefore, the initial "cold set-up session" allowed the radioactive patient to be quickly re-positioned for scanning. Table 1 shows the mean, standard deviation and range of the radiation dose received by a radiotherapy radiographer during these processes. The average total radiation dose to a radiotherapy radiographer during the process of acquiring an RTP PET-CT scan was $5.1 \mu \mathrm{Sv}$.

Figures 2 and 3 show the radiation doses recorded for each radiographer for each individual patient. For Patient 1, the radiation dose received during permanent marking was not recorded; and for Patient 26 the radiation dose measurement was only recorded for one of the radiographers, as a second EPD was not available. 


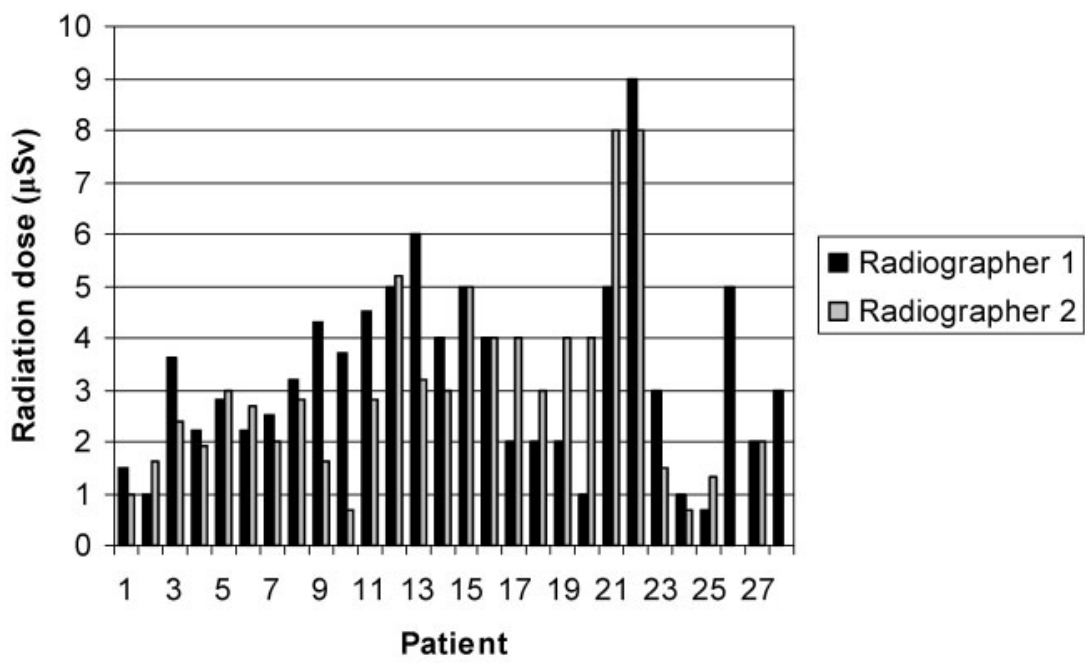

Figure 2. Radiation doses received per patient by each radiotherapy radiographer during "hot set-up session".
The radiation doses received by the radiographers for individual patients are different, as generally one took the lead while the other assisted. During the hot set-up sessions, problems were experienced during the set-up of both of the patients (numbers 21 and 22) for whom the highest doses were recorded. In one case, the patient setup had to be repeated owing to a technical problem with the scanner and, in the other, the patient had a tremor that made set-up difficult. During the "permanent marking" session, the cases for which the radiographers received higher doses than normal were those in which they spent additional time in the room with the patient after the permanent marks had been made, usually because the patient required additional assistance.

\section{Discussion}

The average total radiation dose received by the radiotherapy radiographers was $5.1 \mu \mathrm{Sv}$ per patient. This is comparable to the doses received by nuclear medicine scanning staff working with PET scanners [4, 5]. The two-stage set-up process was effective in reducing radiation dose to the radiographers as, without the "cold set-up session", they would have spent approximately four times as long in close contact with the patient prior to the scan. Based on the measured average radiation doses and times required for set-up and permanent marking, it is estimated that the radiation doses to the radiotherapy radiographers are reduced by approximately a factor of three $(14.1 \mu \mathrm{Sv}$ compared with $5.1 \mu \mathrm{Sv}$ ) by having a "cold set-up session".

The use of a "cold set-up session" also ensures that any difficulties in positioning the patient in the treatment position on the PET-CT scanner, e.g. due to scanner bore

Table 1. Radiation doses received by radiotherapy radiographers during the hot set-up session and permanent marking session

\begin{tabular}{lll}
\hline Task & \multicolumn{2}{l}{ Radiation dose $(\mu \mathrm{Sv})$} \\
\cline { 2 - 3 } & Mean & Range \\
\hline Hot set-up session & $3.1 \pm 1.8$ & $0.7-9.0$ \\
Permanent marking & $2.0 \pm 1.3$ & $0.5-7.0$ \\
\hline
\end{tabular}

size, are resolved before the patient has their ${ }^{18}$ F-FDG injection. A simulator session may be considered as an alternative to the "cold set-up session" on the PET-CT scanner. If the system's bed and bore arrangement could be sufficiently well duplicated, it would be possible to perform the cold set-up prior to the PET-CT study, thus minimising time required on the PET-CT scanner and making booking arrangements more flexible. However, the unique geometry of the PET-CT scanner, and in particular the bore size, may be difficult to simulate on a conventional simulator or CT scanner. The authors identified clear benefits in performing the set-up in situ at the PET-CT scanner. The permanent marking session contributed approximately $40 \%$ of the average dose. The permanent marks are used to provide a reference between the radio-opaque marks visible on the images and the internal anatomy of the patient, including the gross tumour volume. They are subsequently used to set up the patient for treatment. It is standard practice when acquiring planning $\mathrm{CT}$ scans to perform permanent marking after the images have been acquired and checked. This ensures that the permanent marks accurately represent the position of the radio-opaque marks, as seen on the images. Permanently marking the patient before the planning scan in the "cold set-up session" could potentially introduce uncertainties in the set-up process. Also, if a patient's marks do not immediately align to the lasers before scanning, it can be more straightforward to modify the initial non-permanent marks on the patient rather than adjust the position of the patient relative to the lasers.

The results do not indicate that there was any reduction in radiation dose as the radiographers became more experienced in setting up the patients for PET-CT RTP scans. This is likely to be because a radiotherapy radiographer was involved in setting up the procedures to be used, and all radiotherapy radiographers received training before taking part in PET-CT RTP scans. This is very important for what is a new role for radiotherapy radiographers.

The uptake time used in scanning these patients was $45 \mathrm{~min}$, which is routine in our department. If longer uptake times were used, it could be assumed that the radiation dose to the radiotherapy radiographers would be reduced. In addition, if the patients had whole-body 


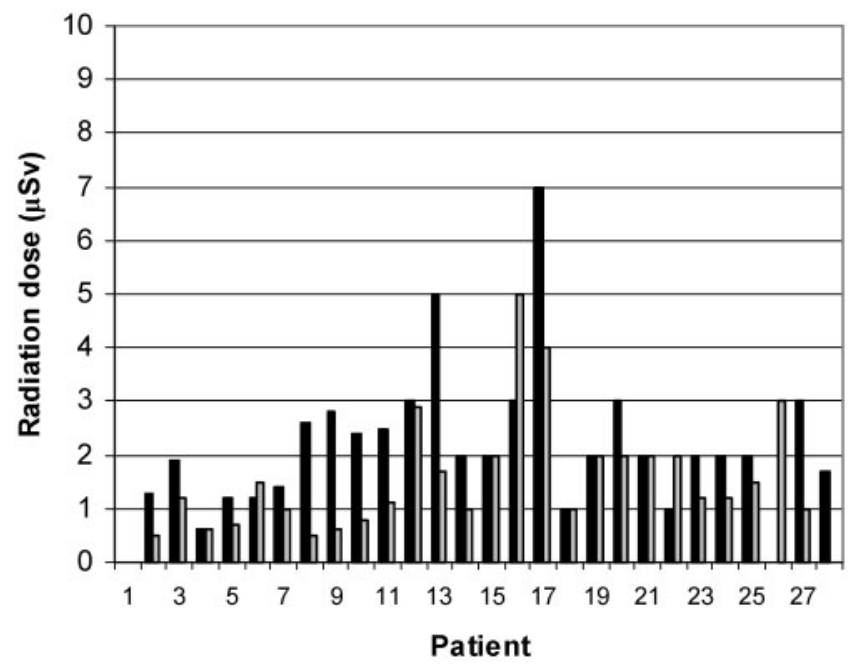

scans rather than scans of shorter extent over the lungs only, the dose during the permanent marking session would also be reduced owing to further decay of ${ }^{18} \mathrm{~F}$. Therefore, the doses reported here may be regarded as upper limits.

Although this study included only NSCLC patients, the results are likely to be applicable to other therapy planning scans using ${ }^{18} \mathrm{~F}-\mathrm{FDG}$, as therapy CT scanning time-slots are generally not modified as a function of site (i.e. the time allocated for the RTP imaging procedure, including the patient set-up, is usually fixed). However, this should be confirmed with site-specific studies.

\section{Conclusions}

Involvement in the PET scanning process during the acquisition of dedicated PET-CT RTP scans is a relatively new role for radiotherapy radiographers. This role incurs an additional occupational radiation dose above that normally received during the PET scanning process. In addition, a dual-bore PET-CT scanner can present additional challenges to the patient positioning process relative to a standard single-bore CT scanner for radiotherapy treatment planning. A "cold set-up session" was effective in reducing the radiation dose to the radiographers involved in the process, with an estimated dose reduction by a factor of three. The average total radiation dose received by the radiographers was $5.1 \mu \mathrm{Sv}$ per patient, which is comparable to the doses received by nuclear medicine scanning staff working with PET scanners.

\section{- Radiographer1 \\ $\square$ Radiographer2}

Figure 3. Radiation doses received per patient by each radiotherapy radiographer during "permanent marking".

\section{Acknowledgments}

We would like to acknowledge the contribution of the following doctors to this study: Dr James Clarke of the Radiology Department, Royal Victoria Hospital, Belfast, and Drs Ruth Eakin, Jonathan McAleese and David Stewart of the Oncology Department, NI Cancer Centre, Belfast City Hospital. We would also like to acknowledge the assistance of the staff of the PET Unit at the Royal Victoria Hospital, Belfast, in performing these scans.

\section{References}

1. Grills IS, Yan D, Black QC, Wong C-YO, Martinez AA, Kestin LL. Clinical implications of defining the gross tumor volume with combination of $\mathrm{CT}$ and ${ }^{18} \mathrm{FDG}-$ positron emission tomography in non-small-cell lung cancer. Int J Radiation Oncology Biol Phys 2007;67:709-19.

2. Leong T, Everitt K, Yuen K, Condron S, Hui A, Ngan SY, et al. A prospective study to evaluate the impact of FDG-PET on CT-based radiotherapy planning for oesophageal cancer. Radiother Oncol 2006;78:254-61.

3. Jarritt PH, Hounsell AR, Carson KJ, Visvikis D, Cosgrove VP, Clarke JC, et al. Use of combined PET/CT images for radiotherapy planning: initial experiences in lung cancer. B J Radiology 2005;Suppl 28:33-40.

4. Benatar NA, Cronin BF, O’Doherty MJ. Radiation dose rates from patients undergoing PET: implications for technologists and waiting areas. Eur J Nucl Med 2000;27:583-9.

5. Roberts FO, Gunawardana DH, Pathmaraj K, Wallace A, Paul LU, Mi T, et al. Radiation dose to PET technologists and strategies to lower occupational exposure. J Nuc Med Technol 2005;33:44-7. 